\title{
T IKATAN BAJA TULANGAN PADA BETON POND ASH SEBAGAI PENGGANTI SEBAGIAN PASIR
}

\author{
Tumingan $^{1, \Xi)}$ dan Salma Alwi ${ }^{2)}$ \\ 1,2 Teknik Sipil, Politeknik Negeri Samarinda. \\ e-mail :1tumingan@polnes.ac.id
}

\begin{abstract}
Pond ash concrete bond is expected to increase bond strength, because in previous studies pond ash concrete resulted in increased mechanical properties of concrete. Bond strength is the bonding mechanism between steel reinforcement and concrete in reinforced concrete construction as the main tool to transfer internal strength between reinforcement and concrete. In this study, a total of thirty-six cylinder concrete with a diameter of $15 \mathrm{~cm}$ and a height of $30 \mathrm{~cm}$. Variations of the test parameters are three reinforcement diameters of $12 \mathrm{~mm}, 16 \mathrm{~mm}$ and $25 \mathrm{~mm}$ and two types of reinforcement namely plain reinforcement and deform reinforcement for normal concrete and pond ash concrete, using a $25 \mathrm{MPa}$ normal concrete mix design and water cement ratio of 0.52 . The results showed that the increase in bond strength on the plain reinforcement from $84.49 \mathrm{~kg} / \mathrm{cm} 2$ to $91.33 \mathrm{~kg} / \mathrm{cm} 2$ an increase of $8.09 \%$, while for deform reinforcement there was in increase from $119.70 \mathrm{~kg} / \mathrm{cm} 2$ in concrete normal to $131.32 \mathrm{~kg} / \mathrm{cm} 2$ an increase of $9.71 \%$ in pond ash concrete. Split collapse occurs in deform reinforcement, whereas in plain reinforcement, slip collapse occurs.
\end{abstract}

Keywords : Bond test, bonding strength, bonding stress, concrete, pond ash concrete

\begin{abstract}
Abstrak
Ikatan beton pond ash diharapkan dapat meningkatkan kekuatan ikatan, karena pada penelitian terdahulu beton pond ash menghasilkan peningkatan sifat mekanik beton. Kekuatan ikatan merupakan mekanisme ikatan antara tulangan baja dan beton dalam konstruksi beton bertulang sebagai alat utama untuk mentransfer kekuatan internal antara tulangan dan beton. Dalam penelitian ini, jumlah benda uji sebanyak tiga puluh enam silinder beton diameter $15 \mathrm{~cm}$ dengan tinggi $30 \mathrm{~cm}$. Parameter pengujian adalah tiga diameter tulangan $12 \mathrm{~mm}, 16 \mathrm{~mm}$ dan $25 \mathrm{~mm}$ serta dua jenis tulangan yakni tulangan polos dan tulangan ulir untuk beton normal dan beton yang ditambah pond ash, menggunakan rancangan campuran beton normal 25 MPa dan factor air semen 0,52. Hasil penelitian menunjukkan bahwa peningkatan kekuatan ikatan pada tulangan polos dari $84,49 \mathrm{~kg} / \mathrm{cm} 2 \mathrm{menjadi} 91,33 \mathrm{~kg} / \mathrm{cm} 2$ terjadi peningkatan sebesar 8,09\%, sedangkan untuk tulangan ulir terdapat peningkatan 9,71\% dari 119,70 $\mathrm{kg} / \mathrm{cm} 2$ pada beton normal menjadi $131,32 \mathrm{~kg} / \mathrm{cm} 2$ pada beton pond ash. Keruntuhan belah terjadi pada tulangan ulir, sedangkan pada tulangan polos, terjadi keruntuhan slip.
\end{abstract}

Kata kunci : Uji ikatan, kekuatan ikatan, tegangan ikatan, beton, beton pond ash

\section{Pendahuluan}

Perkembangan penelitian mengenai material penyusun beton sering dilakukan untuk mencari solusi dengan memanfaatkan sumber daya yang ada disekitar sebagai pengganti campuran, diantaranya dengan menggantikan pasir dengan bahan limbah pond ash.

Pond ash adalah abu batubara hasil proses pembakaran batubara yang dilakukan sebagai bahan bakar untuk menghasilkan energi Listrik, dimana abu batubara ada yang berbentuk halus (fly ash), ada abu batubara berbentuk kasar (bottom ash) dan abu batubara lainnya dibuang dalam suatu kolam/danau/pantai menjadi satu dan dialirkan air pada bagian permukaan untuk menghilangkan/mengendapkan debu abu batubara supaya tidak berterbangan.

Pemilihan bahan beton untuk menghasilkan beton yang kuat menahan tegangan tarik dicoba dengan menambahkan limbah abu batubara (pond ash) menggantikan sebagai agregat halus yang disebut dengan beton pond ash, menjadi beton pond ash yang dibuat dari bahan semen, bahan agregat dan air, ditambah bahan pond ash. Gradasi pond 
ash sama seperti agregat halus, masuk dalam Zona 3.

Dipilih bahan pond ash untuk menggantikan sebagian agregat halus karena besar butirannya termasuk halus dan kecil dapat mengisi celah-celah antara agregat kasar supaya beton menjadi lebih padat sehingga pori-pori dalam campuran beton semakin berkurang. Kepadatan dan kerapatan campuran beton diharapkan mampu meningkatkan ikatan pada campuran beton, maka yang menjadi batasan masalah dalam penelitian ini, yakni : Perilaku ikatan antara beton pond ash dengan baja tulangan dengan penambahan pond ash sebesar $17,5 \%$ dari komposisi campuran beton.

\section{Metode Penelitian}

Evaluasi ikatan antara beton pond ash dengan baja tulangan dalam penelitian ini menjadi Parameter pengujian berdasarkan spesifikasi ASTM C 94-92, meliputi:

a. Direncanakan untuk mutu beton $\mathrm{f}^{\prime} \mathrm{C}=$ $25 \mathrm{MPa}$

b. Pengujian beton pada umur 28 hari

c. Menggunakan baja tulangan ulir dan baja tulangan polos diameter: $12 \mathrm{~mm}$, $16 \mathrm{~mm}$ dan $25 \mathrm{~mm}$

d. Rancangan campuran beton normal (0 \%) dan beton pond ash (17,5 \%) terhadap campuran.

Spesifikasi material untuk penelitian ini menggunakan : Semen portland tipe Semen portland komposit. Agregat kasar menggunakan batu split dari Palu dengan spesifikasi diameter $19 \mathrm{~mm}$, agregat halus menggunakan agregat halus alami atau Pasir juga dari Palu dengan diameter maksimum 4,75 mm. Untuk beton normal menggunakan tiga bahan pokok diatas yakni Semen, agregat dan air. Sedangkan untuk campuran beton pond ash diberi bahan tambahan abu batubara (pond ash) sebesar 17,5 \% terhadap komposisi dalam campuran.

Benda uji penelitian ini adalah beton silinder yang dipasang tulangan di bagian tengahnya. Untuk kemudahan dalam pembongkaran/pelepasan beton silinder dari cetakan, dipilih cetakan dari pipa paralon diameter $15 \mathrm{~cm}$ dengan tinggi 30 cm pada bagian bawah ditutup papan plywood diberi lobang sesuai diameter tulangan yang dipasang. Penempatan baja tulangan pada bagian tengah silinder dengan panjang tertanam Ld 12,5 cm pada bagian bawah dan bagian atas membentuk garis lurus vertical pada pusat sumbu silinder benda uji. Benda uji beton silinder dipadatkan sampai tidak muncul lagi gelembung udara. Perawatan beton dilakukan dengan menutup benda uji menggunakan kain goni selama 24 jam, silinder dibongkar dengan memotong cetakan silinder pipa paralon, selanjutnya silinder beton dirawat dengan cara merendam dalam air selama 7 hari.

Proses pengujian dilakukan dengan menarik kedua ujung tulangan secara langsung (pull out test) setelah dilakukan perawatan 7 hari dengan cara direndam dalam air dan dibiarkan pada suhu ruangan sampai umur 28 hari. Pemberian beban/gaya dilakukan dengan menjepit kedua tulangan dan menarik menggunakan mesin uji universal (universal testing mechine) dengan hasil yang diperoleh berupa data pembebanan (load) dan data keruntuhan (displacement) berupa lepasnya tulangan dari beton tanpa merusak betonnya (slip) atau beton akan patah/hancur tetapi masih melekat pada tulangan (splitting). Bentuk pengujian ikatan antara baja tulangan dengan beton dalam penelitian ini, ditunjukkan pada gambar 1 .

\section{Hasil dan Pembahasan}

Tahap awal penelitian dengan melakukan pengujian karakteristik atau sifat fisik material yang digunakan yaitu gradasi dari batu pecah / agregat kasar dan gradasi pasir / agregat halus. Hasil pengujian sifat fisik material agregat 
halus/pasir dan agregat kasar/batu pecah hasil seperti pada gambar 2 dan gambar 3 . Selain pengujian sifat fisik gradasi agregat, juga dilakukan pengujian berat jenis dan penyerapan agrgat, dengan hasil disusun dalam Tabel 1, berikut.

Tabel 1 Hasil pengujian berat jenis dan pengujian kadar air.

\begin{tabular}{lcc}
\hline Hasil Uji & Agregat Halus & Agregat Kasar \\
\hline Bj. kering & 2,534 & 2,668 \\
Berat jenis SSD & 2,565 & 2,692 \\
Kadar Air & 0,390 & 0,515 \\
Penyerapan & 1,225 & 0,872 \\
\hline
\end{tabular}

Data hasil pengujian gradasi, berat jenis dan penyerapan agregat, digunakan sebagai dasar perhitungan rancangan campuran beton (mix design beton) dengan menetapkan mutu beton f'c 25 MPa dengan faktor air semen tetap 0,52 didapatkan hasil perbandingan campuran untuk produksi beton $1 \mathrm{~m} 3$, masingmasing beton seperti tabel 2, berikut :

Tabel 2 Perhitungan kebutuhan bahan $1 \mathrm{~m}^{3}$.

\begin{tabular}{lrr}
\multicolumn{1}{c}{ Nama bahan } & Beton normal & Beton pond ash \\
\hline Semen PCC Tonasa & $384,62 \mathrm{~kg}$ & $384,62 \mathrm{~kg}$ \\
Agregat kasar ex. Palu & $1183,04 \mathrm{~kg}$ & $1183,04 \mathrm{~kg}$ \\
Agregat halus ex. Palu & $639,71 \mathrm{~kg}$ & $319,85 \mathrm{~kg}$ \\
Pond ash & - & $219,52 \mathrm{~kg}$ \\
Air & $212,64 \mathrm{~kg}$ & $312,98 \mathrm{~kg}$ \\
Jumlah bahan & $2.420,0 \mathrm{~kg}$ & $2.420,0 \mathrm{~kg}$ \\
\hline
\end{tabular}

Hasil pengujian yang diperoleh dari masing-masing parameter pengujian berupa gaya tarik maksimum dan tipe keruntuhan. Pada benda uji yang menggunakan tulangan ulir, terlihat bahwa keruntuhan dengan rusaknya silinder beton yang terpotong atau patah (splitting), Sedangkan keruntuhan dengan terlepasnya baja tulangan dari ikatan/adhesi dengan beton berupa slip terjadi pada benda uji yang menggunakan tulangan polos, pola keruntuhan yang terjadi ditunjukkan pada gambar 3. Nilai kekuatan ikatan/adhesi antara tulangan dengan beton pada masing-masing benda uji ditunjukkan gambar 4. Besarnya gaya ikatan/adhesi dihitung dari nilai gaya tarik maksimum yang ditahan dibagi luas permukaan tulangan yang tertanam.

Untuk mengetahui besarnya kekuatan tarik pengaruh ikatan/adhesi antara baja tulangan dengan beton, baik beton normal atau beton pond ash, dihitung dengan tahapan sebagai berikut :

1. Memberikan pembebanan berupa gaya tarik dengan menekan tombol Up pada mesin Tarik universal, mengamati pola retak dan mencatat bacaan dial manometer sampai pada saat terjadi keruntuhan. Hasil perhitungan ikatan pada masing-masing diameter tulangan dan jenis beton seperti yang ditampilkan pada gambar 4, sedangkan untuk ikatan karakteristik diperlihatkan pada gambar 5 .

2. Menghitung kuat ikatan/adhesi (U) menggunakan rumus:

$$
\mathrm{U}=\frac{P}{\pi d_{b} l_{d}}\left(\mathrm{~kg} / \mathrm{cm}^{2}\right)
$$

3. Kuat ikatan atau kuat tarik karakteristik (Ubk), adalah hasil hitungan dari kuat ikatan rata - rata (Ubm) dikurangi faktor kemencengan (k) dikali standar deviasi (s).

Kuat ikatan karakteristik hasil uji

$$
\left(\mathrm{U}_{\mathrm{bk}}\right)=\mathrm{U}_{\mathrm{bm}}-\mathrm{k} . \mathrm{s}
$$

$$
\text { Dimana : }\left(\mathrm{U}_{\mathrm{bm}}\right) \rightarrow \bar{x}=\frac{1}{n} \sum_{i=1}^{n} x_{i} ; \quad ;
$$

$$
\begin{aligned}
& k=\frac{\sum_{i=1}^{n}\left(x_{i}-\bar{x}\right)^{3}}{n \cdot s^{3}} \\
& s=\sqrt{\frac{\sum_{i=1}^{n}\left(x_{i}-\bar{x}\right)^{2}}{n-1}}
\end{aligned}
$$

Hasil perhitungan kekuatan ikatan baja tulangan dengan beton terhadap masingmasing diameter tulangan ditunjukkan pada grafik gambar 4 dan grafik gambar 5 yang menyatakan hubungan antara kekuatan ikatan terhadap diameter berbagai tulangan pada beton normal maupun beton pond ash.

Peningkatan kekuatan ikatan pada beton pond ash yang menggunakan jenis 
tulangan ulir, menunjukkan kecenderungan peningkatan kekuatan ikatan yang signifikan, dengan bentuk keruntuhan beton terpotong (splitting). Hal ini terjadi karena massa beton pond ash lebih padat dibanding beton normal dengan rongga/pori terisi bahan pond ash yang lebih halus dari pasir yang menunjukkan adanya perbaikan microstruktur antara matriks beton meningkatkan kapasitas tarik betonnya.

Berdasarkan grafik Gambar 4, hasil kekuatan ikatan untuk beton normal dan beton pond ash menghasilakn ikatan yang hampir sama bahkan beberapa kondisi hasilnya sama, hal ini terjadi karena bentuk keruntuhan berupa lepasnya ikatan tulangan terhadap beton (slip) ditandai dengan kerusakan beton pada ujung/permukaan tertanamnya baja tulangan yang menggunakan jenis tulangan polos.

Keruntuhan benda uji yang menggunakan tulangan ulir, kekuatan ikatan meningkat seiring dengan besarnya diameter tulangan yang digunakan dengan bentuk keruntuhan adalah hancur/patah silinder benda uji pada posisi bidang pemisah antar tulangan yang tertanam dengan keruntuhan jenis pull-out, mengakibatkan pelepasan iaktan antara bahan pembentuk beton atau lepasnya ikatan antar agregat lebih kecil disbanding ikatan antara tulangan dengan beton

\section{Kesimpulan}

Memperhatikan bentuk grafik ikatan antara beton dan tulangan dengan berbagai diameter yang digunakan pada beton normal dan beton pond ash terhadap kekuatan ikatan (bonding strength) untuk benda uji berbentuk silinder, kami simpulkan :

a. Kekuatan ikatan pada beton pond ash meningkat dibanding beton normal karena bahan pond ash lebuh halus butirannya dibanding pasir disinyalir bahan pond ash dapat mengisi roggarongga kecil antar partikel agregat.

b. Terdapat peningkatan kekuatan ikatan pada tulangan polos dari 84,49 $\mathrm{kg} / \mathrm{cm} 2$ pada beton normal meningkat menjadi 91,33 $\mathrm{kg} / \mathrm{cm} 2$ pada beton pond ash atau terjadi peningkatan sebesar 8,09\%, sedang benda uji menggunakan tulangan ulir juga mengalami peningkatan dari 119,70 $\mathrm{kg} / \mathrm{cm} 2$ pada beton normal meningkat menjadi $131,32 \mathrm{~kg} / \mathrm{cm} 2$ pada beton pond ash atau terdapat peningkatan sebesar 9,71\%.

c. Keruntuhan yang terjadi pada benda uji menggunakan tulangan ulir berupa hancur/belah pada silinder beton (splitting failure) atau terlepasnya ikatan agregat/pertikel beton. Keruntuhan benda uji menggunakan tulangan polos, berupa keruntuhan terlepasnya ikatan tulangan terhadap beton (slip).

\section{Daftar Pustaka}

[1] ACI 209.2R-08, 2008, Guide for Modeling and Calculating Shrinkage and Creep in Hardened Concrete. Reported by ACI Committee 209 ISBN 978-0-87031-278-6. Farmington Hills, MI 48331 U.S.A.

[2] ACI 318-14, 2014, Building Code Requirements for Structural Concrete. ISBN: 978-0-87031-930-3 American Concrete Institute 38800 Country Club Drive Farmington Hills, MI 48331, September 2014.

[3] ASTM 1992, Annual Book of ASTM Standars. Section 4 Construction, Volume 04.02 Concrete Aggregates, Philadelphia.

[4] ASTM C 150, 2007. Standard Specification for Portland Cement, Juni 2007.

[5] ASTM C 33-90. 1992. Standard specification for concrete aggregates.

[6] ASTM C 39/C39M - 12a, Standard Test Method for Compressive Strength of Cylindrical Concrete Specimens, October 2012. 
[7] Badan Pusat Statistik Kabupaten Kutai Kartanegara, 2017. Katalog Kecamatan Tenggarong Seberang Dalam Angka 2017. http://kukarkab.bps.go.id/.

[8] Badan Pusat Statistik Provinsi Kalimantan Timur, 2016. Produksi Batubara 2009-2015, November 07, 2016. https://kaltim.bps.go.id/.

[9] Bagwan, K. M., Kulkarni, Dr. S. S. 2014, A Study of Characteristic and Use of Pond Ash for Construction, Website: www.ijetae.com (ISSN 2250-2459, ISO 9001:2008 Certified Journal, Volume 4, Issue 6, June 2014.

[10] Bharathi Ganesh, H. Sharada Bai, R. Nagendra and B.K. Narendra. 2012, Characterization of Pond Ash as Fine Aggregate in Concrete, Proceedings of International Conference on Advances in Architecture and Civil Engineering (AARCV 2012), 21st - 23rd June 2012.

[11] Davis, H. E ; Troxell, G. E and Hauck, George F. W. (1982) The Testing of Engineering Materials. McGraw-Hill Inc, New York.

[12] Kadam, M.P., and Patil, DR.Y.D., 2013, Effect of Bottom Ash as sand replacement on the properties of concrete with different W/C/ ratio, International Journal of Advanced Technology in Civil Engineering, ISSN: 2231 -5721, Volume-2, Issue1.

[13] Mehta, P.K and Monteiro,P.J.M (2005). Concrete: Microstructure, Properties and Materials, 3rd Ed, McGraw-hillProfessional.

[14] Neville, A M; Brooks, J J. (2010) Concrete Technology, second edition, Longman Scientific \& Technical.

[15] Rathod, Mihir., Sharma, Shipra. 2015, Review on the Use of both FlyAsh and Pond-Ash in Concrete Mix Design. IJSRD / Vol. 2/Issue 12/2015/056.
[16] Singh, Malkit; Siddique, Rafat., 2013, Effect of coal bottom ash as partial replacement of sand on properties of concrete, Resources, Conservation and Recycling 72 (2013) 20- 32.

[17] SNI 03-2834-2000, 2000. Tata cara pembuatan rencana campuran beton normal, Badan Standardisasi Nasional.

[18] SNI 03-2847-2013, 2013. Tata Cara Perhitungan Struktur Beton Untuk Bangunan Gedung, Departemen Pekerjaan Umum.

[19] SNI 15-7064-2004, 2004. Semen Portland Komposit, Departemen Pekerjaan Umum.

[20] SNI 2416:2014, 2014. Spesifikasi Abu Terbang Batubara dan Pozzolan Alam Mentah Atau Yang Telah Dikalsinasi Untuk Digunakan Dalam Beton, Departemen Pekerjaan Umum.

[21] Tumingan, (2017) Splitting Tensile of Concrete With Pond Ash as Replacement of Fine Aggregate, International Journal of Innovative Research in Advanced Engineering ( IJIRAE ), Volume 4, Issue 10, October 2017.

[22] Tumingan, M. W Tjaronge, Rudy Djamaluddin and Victor Sampebulu, (2016), Penyerapan dan Porositas pada Beton Menggunakan Bahan Pond Ash Sebagai Pengganti Pasir, Politeknologi VOL. 15 No. 1 Januari 2016, ISSN: 2407-9103.

[23] Tumingan, Tjaronge, $\mathrm{M}$ W., Djamaluddin, Rudy., dan Sampebulu, Victor, 2017. Compression Strength Concrete With Pond Ash Lati Berau. IPTEK Journal Of Procendings Series.

[24] Tumingan, Tjaronge, M W., Djamaluddin, Rudy., dan Sampebulu, Victor., Compression Strength Of Concrete With Pond Ash As Replacement Of Fine Aggregate, ARPN Journal of Engineering and 
Applied Sciences, Vol. 9, No. 12, December 2014.

[25] Wegen, Gert van der; Hofstra, Ulbert; Speerstra, John., 2013. Upgraded MSWI Bottom Ash as
Aggregate in Concrete, Waste Biomass Valor DOI 10.1007/s12649013-9255-6 Received: 18 October 2012 / Accepted: 10 June 2013

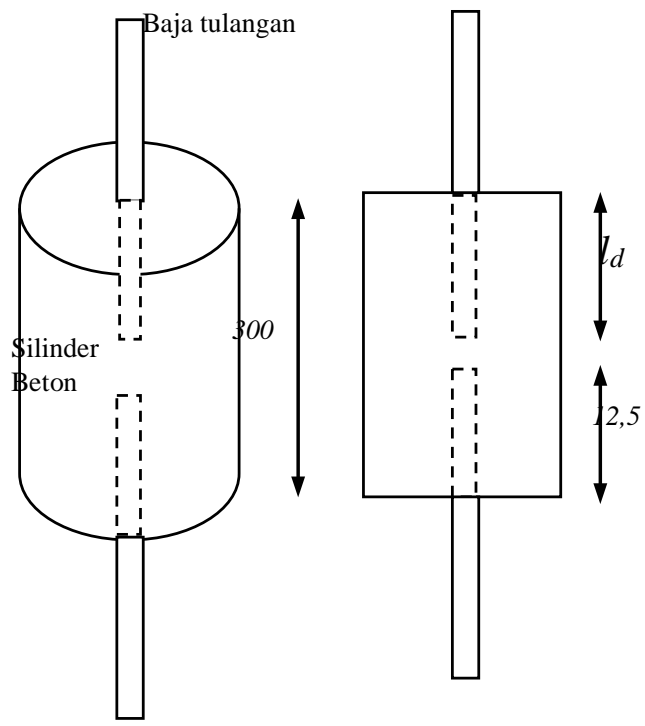

Gambar 1. Set up pengujian Ikatan Baja Beton
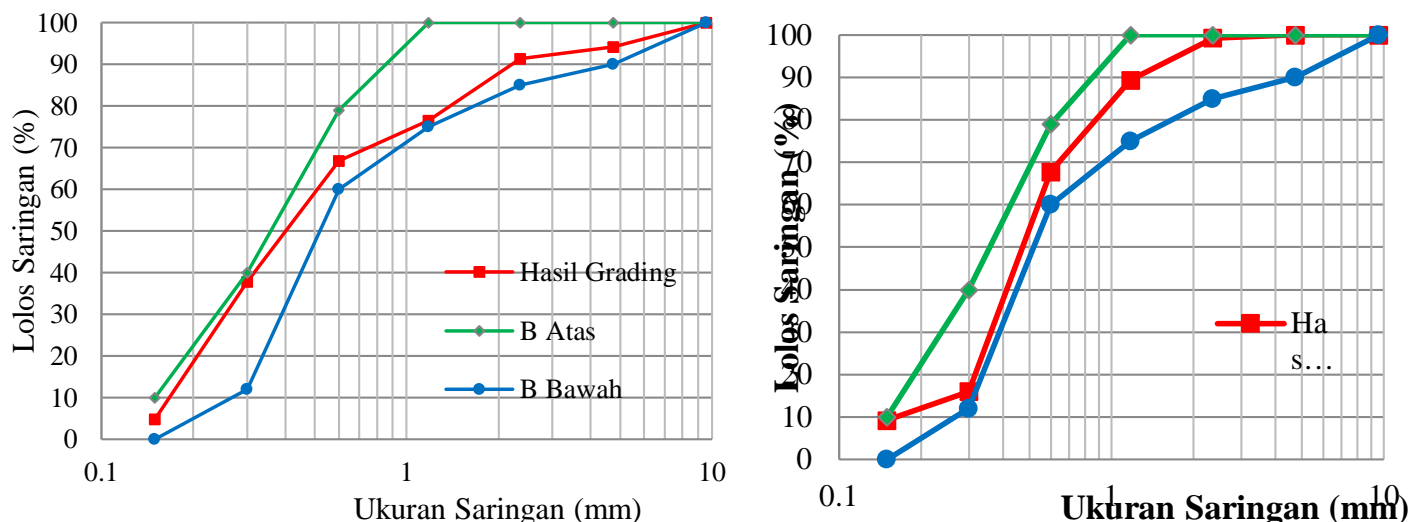

Gambar 2. Grafik analisa agregat halus Zona 3, kiri Pasir, kanan Pond ash.
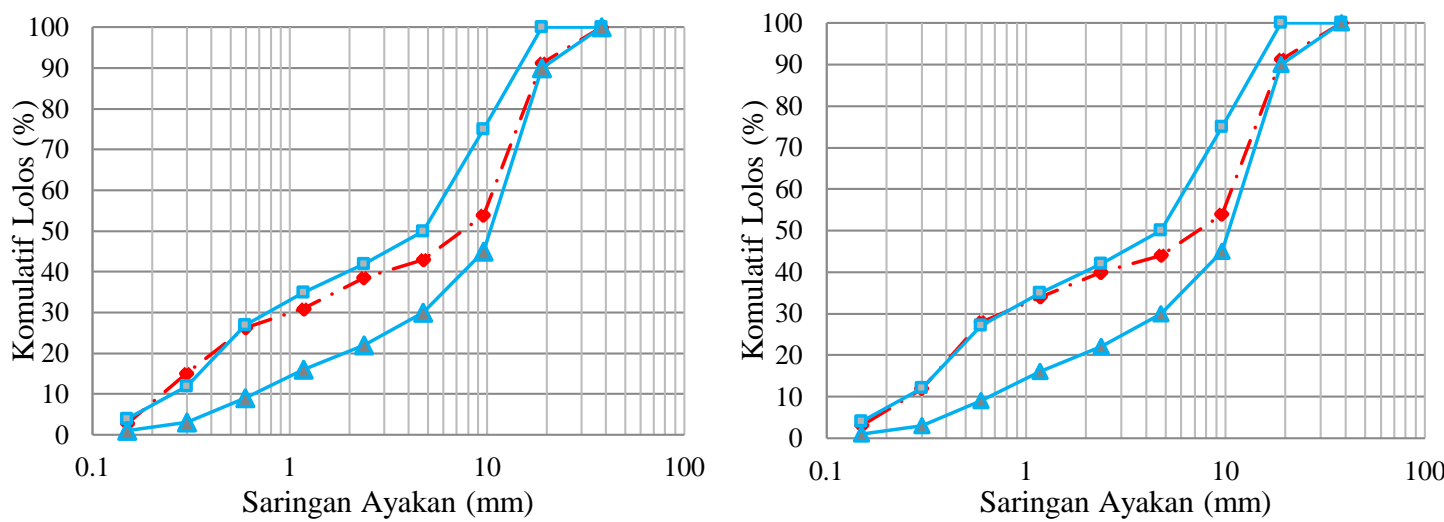

Gambar 3. Grafik analisa agregat gabungan 35\% Pasir + 65\% Batu Pecah dan pond ash 17,5\%. 


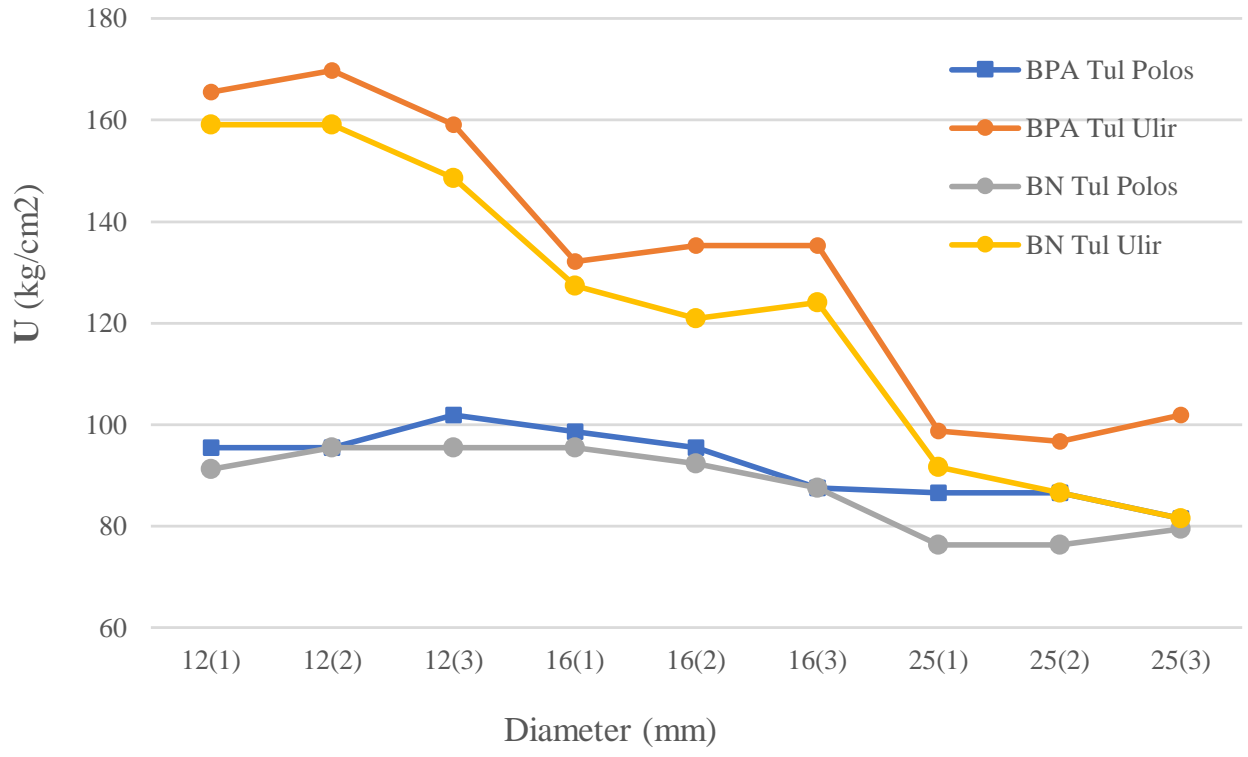

Gambar 4. Perbandingan Kuat ikatan pada beton normal dan beton pond ash.

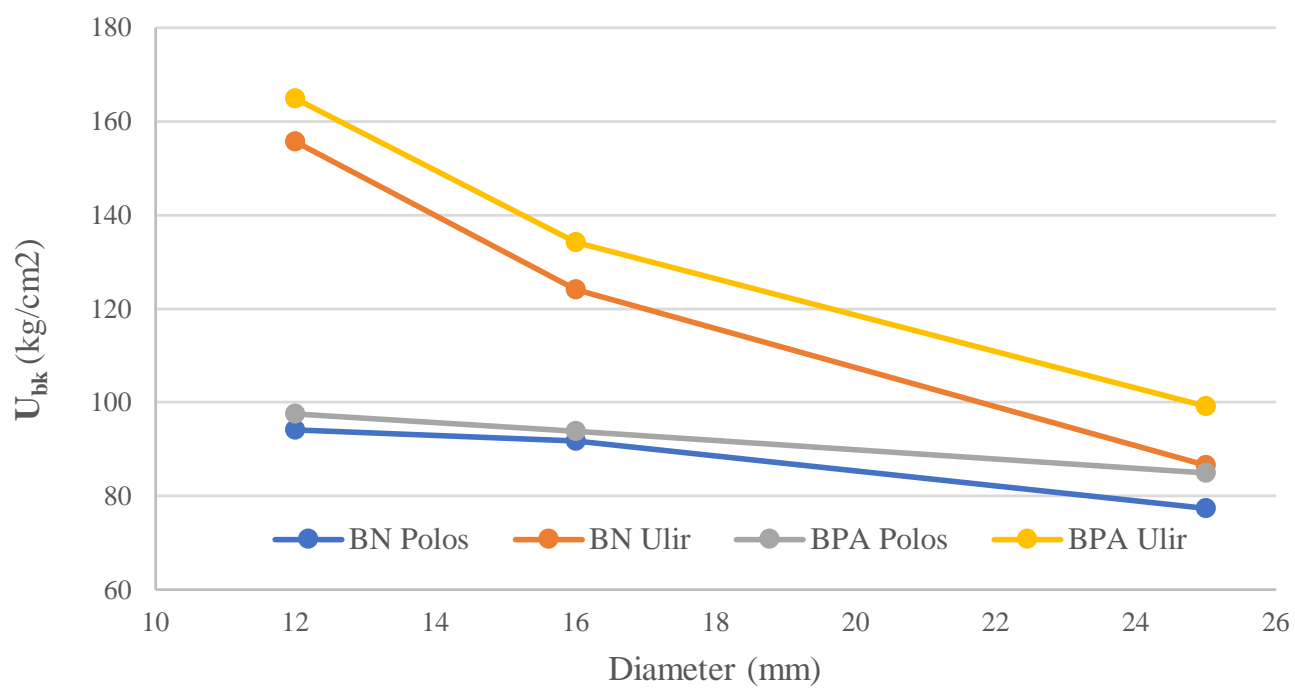

Gambar 5. Perbandingan Kuat ikatan karakteristik terhadap diameter tulangan.

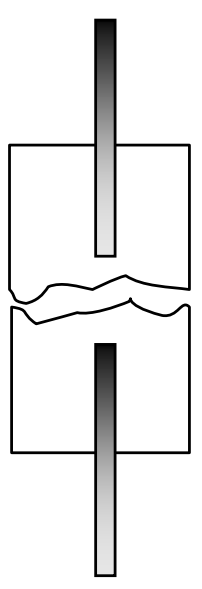

a) Runtuh

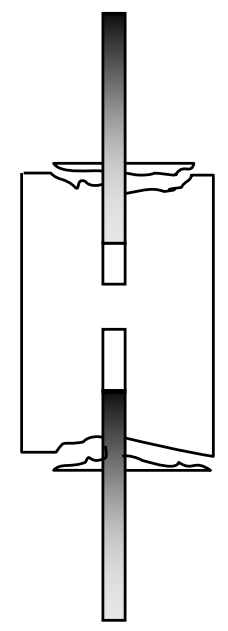

b) Selip

Gambar 6. Bentuk keruntuhan Ikatan Baja Beton 
Tumingan dan Salma Alwi, T Ikatan Baja Tulangan... 